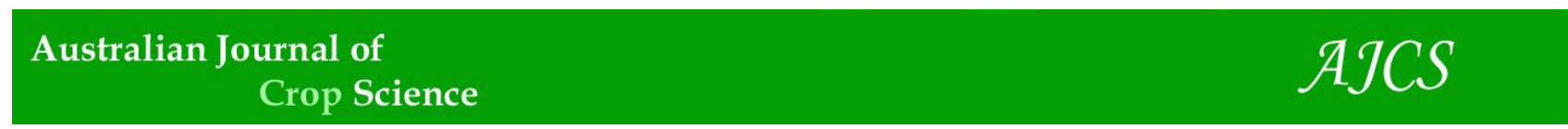

AJCS 11(10):1320-1326 (2017)

ISSN:1835-2707

doi: 10.21475/ajcs.17.11.10.pne606

\title{
Refining the tetrazolium test for evaluation of Cattley a labiata and $C$. tigrina seeds viability
}

\author{
Silvério Takao Hosomi ${ }^{1}$, Thatiane Bonome de Souza $^{2}$, Ceci Castilho Custódio ${ }^{3}$, Nelson Barbosa \\ Machado Neto ${ }^{3 *}$
}

${ }^{1}$ Biological Sciences College and Post Graduation Agronomy Program at UNOESTE, Presidente Prudente, SP, CEP 19067175, Brazil

${ }^{2}$ Biological Sciences College at UNOESTE, Presidente Prudente, SP, CEP 19067175, Brazil

${ }^{3}$ Post Graduation Agronomy Program and Agricultural Sciences College at UNOESTE, Presidente Prudente, SP, CEP 19067175, Brazil

\section{*Corresponding author: nbmneto@unoeste.br}

\begin{abstract}
The evaluation of seed physiological quality can help taking quick decision about the use or disposal of lots for conservation. The tetrazolium test is one of the most traditional in the analysis of seeds quality. Optional preconditioning procedures have improved the efficiency of this test. This work compared the efficiency of different preconditioning procedures, the buffered solution, concentrations and exposure time to tetrazolium solution in assessing the quality of orchid seeds of Cattleya labiata and Cattleya tigrina lots. The analysis was made through magnification of digital images. For preconditioning evaluation, two seed lots were aliquoted and submitted to different treatments: $10 \%$ sucrose solution, $10 \%$ glucose solution and water at room temperature for 24 hours. After preconditioning, seeds were immersed in tetrazolium solutions - prepared with buffer or water - at concentrations of 0.1, 0.5 and $1.0 \%$ for periods of 3,12 and 24 hours, at $40{ }^{\circ} \mathrm{C}$, in a water bath, in the dark. The experiment design was arranged in a factorial $4 \times 3 \times 3 \times 2$ and the mean comparison was made by Tukey test at $5 \%$ probability. Tetrazolium test in preconditioned orchid seeds allowed better visualization of red viable seeds. Tetrazolium test in orchid seeds preconditioned in glucose $10 \%$ solution or sucrose $10 \%$ solution was more effective for viable seeds visualization. Diluting tetrazolium salt in buffered solution or water made no difference for the results. Maintaining seeds in contact with tetrazolium $1 \%$ solution for 24 hours provided the higher viability values for both seed lots.
\end{abstract}

Keywords: Orchidaceae, Preconditioning, Buffer solution. Abbreviations: GVI_Germination velocity index; Tz_Tetrazolium.

\section{Introduction}

Orchids (Orchidaceae family) are the second largest plant group among Angiosperms, ranged in more than 26,000 species belonging to 736 genera (Chase et al., 2015). Present in every continents - except Antarctica - and particularly numerous and diverse as epiphytes in the humid tropics, orchids have long fascinated researchers for its remarkable survival strategies, floral and vegetative morphology and pollination syndromes (Fay and Chase, 2009). Still, orchids face an uncertain future due to the existence of a growing number of unconscionable collectors, the climate change impacts and the loss of their habitats (Swarts and Dixon, 2009). Despite the progress of plant conservation through the use of in situ and ex situ protective strategies in botanical gardens and seed banks, new approaches are needed for some of the most endangered species. Ex situ seed conservation strategies, such as in vitro storage and cryopreservation, can complement in situ strategies and ensure the biodiversity preservation of species whose habitats are very threatened (Reed et al., 2011). The establishment of a genetic bank through seed storage is extremely important, both for wild species, that carry their own characteristics, and for breed species (Yam et al., 2009). To test the viability of seeds to be stored in banks, or those that have been already stored for a period, samples must undergo viability tests. Therefore, one of the possibilities is germination test, which determines the seeds germination potential (Carvalho and Nakagawa, 2012). However, this technique shows limitations related to lots differentiation, delay in obtaining results (Custódio, 2005) and, particularly for orchids, requires a long period of time, specialized techniques and elevated implementation costs. This is because orchid seeds need to establish a relationship with mycorrhizal fungi and / or use an appropriate culture medium to germinate (Alvarez-Pardo and Ferreira, 2006). Time required for symbiotic germination can vary between one and a few months or even a year, depending on the species and the seeds lot (Rasmussen, 2011), as well as the ability of a particular isolated fungus to induce germination (Bertolini et al., 2011). The use of rapid tests in verifying seeds quality is mainly important to speed decisions up about the management of lots during post-harvest stages. Tests that require short periods are related to the initial deterioration events, and are based on cell membranes integrity and in the reduction of seed enzymes and respiratory activity, like tetrazolium test (Marcos Filho, 2015). This test has been an interesting alternative for its quality and speed in determining seeds viability and vigor, generally allowing results achievement in less than 24 hours (Dias and Alves, 2008). 
In commercial crops, such as soybeans, beyond enabling the evaluation of seed lots viability and vigor, the tetrazolium test provides data about the possible causes responsible for the reduction of its quality: mechanical and moisture damage, and those caused by bugs, which are the most common problems that affect the physiological quality of seeds. Furthermore, drying damage, water stress and frost can also be easily identified by its use. The possibility of a broad diagnosis has been largely responsible for the high adoption of this test in Brazil, because besides pointing quality reduction problems of seeds, the test can identify the origin of these problems when applied at various stages of the production system, allowing corrective actions and resulting in the production of high quality seeds (França Neto, 1998). Tetrazolium test is based on the detection of dehydrogenase enzymes activity, in particular malic acid dehydrogenase, that reduces 2,3,5 triphenyl tetrazolium chloride salt in seed living tissues, which in turn transfers hydrogen ions to the salt (Marcos Filho, 2015). When seeds are immersed in tetrazolium solution, it diffuses through the tissues, promoting the reduction reaction in living cells. It results in the formation of a red compound, not diffusible, known as trifenilformazan. Such coloration indicates the occurrence of respiratory activity in mitochondria and, consequently, the viability of the tissue. Dead tissues (not viable) do not react with the solution, maintaining their natural color (Lazarotto et al., 2011).

There are some procedures, known as preconditioning, that facilitate the penetration of tetrazolium solution into the tissues to be evaluated. Many preconditioning treatments have been used in seeds of forest species, such as cutting, scarification and soaking in water (Oliveira et al., 2001; Mendonça et al., 2006).

According to Hosomi et al, (2011), the comparison between in vitro germination rates of various species of the genus Cattleya with the results obtained by tetrazolium test applied to seeds submitted to preconditioning in a $10 \%$ sucrose solution, showed similar viability rates, demonstrating the importance of using sucrose solution for preconditioning. Custódio et al. (2016) obtained similar results for Dactylorrhyza and Vanda; the same has been described for Aerides maculosum (Deepti et al., 2013) and Aerides ringens (Deepti et al., 2015).

According to Custódio et al. (2016), using vacuum increased the tetrazolium solution infiltration into orchid seeds of Dactylorhiza fuchsii, which has hard tegument; the same paper reports the use of sodium hypochlorite for integument clarification in Vanda curvifolia, wich has dark seeds, enabling better tetrazolium color visualization. Salazar-Mercado (2012) points out that the use of $1.0 \%$ sodium hypochlorite was important to tegument scarification in Cattleya mendelli, which allowed better tetrazolium salt penetration, the same being true for Thelymitra pauciflora and Prasophyllum pruinosum (Dowling and Jusaitis, 2012). Ideally, tetrazolium solution $\mathrm{pH}$ should be between 6 and 8 , which fundamentally depends on the water quality used in its preparation. However, even solutions prepared with distilled water are acid, having lower $\mathrm{pH}$ than recommended. Accordingly, embryo staining occurs inappropriately, causing seed viability misinterpretation. This problem can be avoided by using a phosphate buffer solution to prepare tetrazolium, which ensures the $\mathrm{pH}$ maintenance within the acceptable range (Dübbern de Souza, 1994; Salazar-Mercado, 2012).

Therefore, in addition to preconditioning, there are some critical parameters for obtaining reliable results about seed quality: the tetrazolium solution concentration, the exposure time to tetrazolium, the $\mathrm{pH}$ solution and the proper evaluation of seed coloration.
This study aimed to verify the efficiency of different preconditioning methods, the influence of buffered solution, of concentration and exposure time to tetrazolium solution in assessing the quality of orchid seeds lots.

\section{Results and Discussion}

Cattleya tigrina presented a total seed germination of $94.6 \%$ with $9.75 \pm 0.65$ GVI, while Cattleya labiata had $35.9 \%$ germination with of $2.51 \pm 0.41$ GVI (Figure 2). Data shows that $C$. labiata seeds had low viability. Figure 3 reveals that C. labiata seeds took longer to germinate and, on the seventh day, many seeds had not germinated, showing undeveloped protocorm compared to $C$. tigrina, which had already grown up in the third week, some of them having rhizoids as featured in figure 3.

Regarding preconditioning needs of $C$. labiata and $C$. tigrina seeds, the use of $10 \%$ glucose or $10 \%$ sucrose solution provided the best results for tetrazolium test, differing from the other treatments. For $C$. tigrina the absence of preconditioning showed the worse viability. For C. labiata, which had low viability, the use of water and the absence of preconditioning were not statistically different (Table 1).

According to Dübbern Souza (1994), the use of buffer would be needed to maintain the optimal $\mathrm{pH}$ range for the test between 6.0 and 8.0 - since the use of acid water may cause misinterpretation of seed viability. However, according to Table 1, which compares the use of distilled water and phosphate buffer solution for tetrazolium dilution, it was determined that there were no significant differences in all preconditioning treatments. For Soares et al. (2014) using $0.5 \%$ tetrazolium buffered solution was better to evaluate Cattleya labiata (autumnalis $\mathrm{x}$ f. alba) and the use of $0.125 \%$ aqueous solution was the most suitable for Brassavola tuberculata, Cattleya labiata f. amoena and Dendrobium antenatum. However, it is important to emphasize that, in the experiments of Lallana and García (2013), Macedo et al. (2014) and Soares et al. (2014) seeds were incubated at room temperature unlike the work of Hosomi et al. $(2011,2012)$ and Custódio et al. (2016) which followed the preconized temperature for $\mathrm{Tz}$ testing at $40{ }^{\circ} \mathrm{C}$.

Table 1 still shows that the type of preconditioning applied to the samples significantly influences the results obtained. Seeds without preconditioning had the lowest viability values and the use of $10 \%$ glucose and $10 \%$ sucrose solution showed the highest values.

In the evaluation of optimal tetrazolium concentration, it was verified that the higher the salt concentration, the better detection of the seeds viability (Figure 4). Tests using 1.0\% tetrazolium solution detected the great viability values: $79 \%$ for C. tigrina and $37 \%$ for C. labiata. These data support the work of Hosomi et al. (2011), which also indicates this concentration as the best. Regarding seeds exposure time to tetrazolium solution, it was realized that immersion for 24 hours enabled the detection of the best viability values for the two species analyzed $-80 \%$ for C. tigrina and $45 \%$ for $C$. labiata - which are significant results concerning other time intervals (Figure 4).

The interaction between preconditioning and concentration of tetrazolium solution for $C$. labiata seeds showed that the higher the concentration of tetrazolium solution, the greater detection of viability (Figure 5-I). However, statistically, only preconditioning in $10 \%$ sucrose solution followed by the use of $1.0 \%$ tetrazolium showed significant differences compared to other conditions. Regarding seeds exposure time to tetrazolium solution, $24 \mathrm{~h}$ period allowed the detection of the best significant viability values for all preconditioning treatments, followed by exposure for 12 hours (Figure 5-II). 
Table 1. Cattleya labiata and Cattleya tigrina seed viability (\%) due to control, preconditioning in water, glucose and sucrose, submitted to tetrazolium diluted in water or buffer solution.

\begin{tabular}{|c|c|c|c|c|}
\hline \multirow{3}{*}{ Preconditioning } & \multicolumn{4}{|c|}{ Viability (\%) } \\
\hline & \multicolumn{2}{|c|}{ Cattleya labiata } & \multicolumn{2}{|c|}{ Cattleya tigrina } \\
\hline & Without buffer & With buffer & Without buffer & With buffer \\
\hline Control & $29^{\mathrm{Ba}}$ & $27^{\mathrm{Ba}}$ & $45^{\mathrm{Ca}}$ & $46^{\mathrm{Ca}}$ \\
\hline Water & $30^{\mathrm{Ba}}$ & $30^{\mathrm{Ba}}$ & $70^{\mathrm{Ba}}$ & $67^{\mathrm{Ba}}$ \\
\hline Glucose & $38^{\mathrm{Aa}}$ & $35^{\mathrm{Aa}}$ & $76^{\mathrm{Aa}}$ & $75^{\mathrm{Aa}}$ \\
\hline Sucrose & $38^{\mathrm{Aa}}$ & $36^{\mathrm{Aa}}$ & $77^{\mathrm{Aa}}$ & $74^{\mathrm{Aa}}$ \\
\hline
\end{tabular}

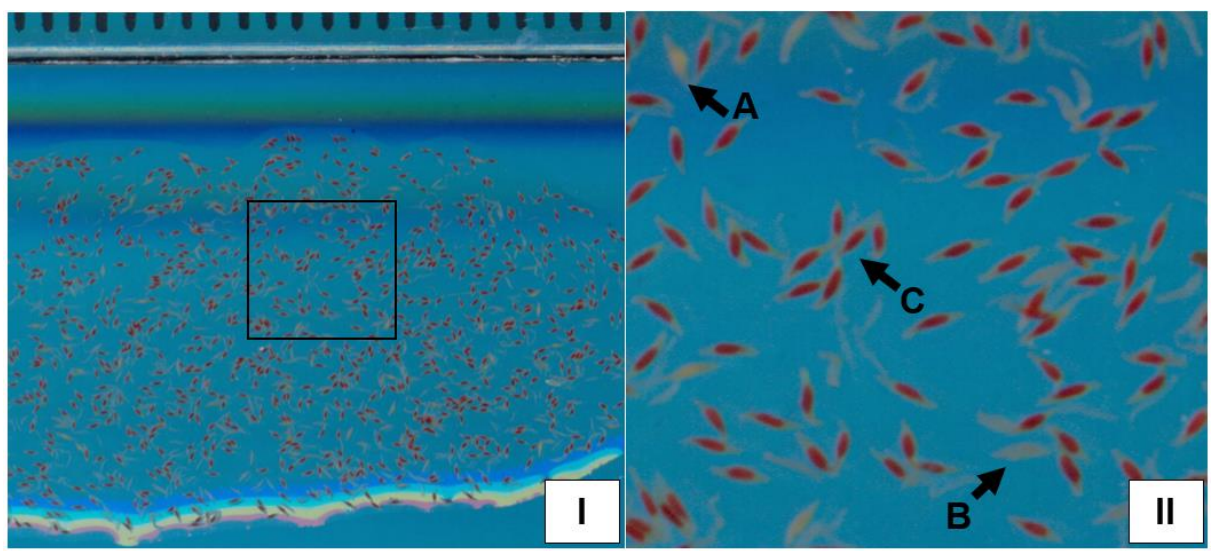

Fig 1. Cattleya tigrina seeds preconditioned in sucrose solution, submitted to tetrazolium test at $1 \%$ buffered solution, for 24 hours. I - Slide scanned image with ruler scale reference in millimeters; II - Slide field expanded image where: A- nonviable seeds (white color), B- straw (no embryo seeds) and C-viable seeds (red color).

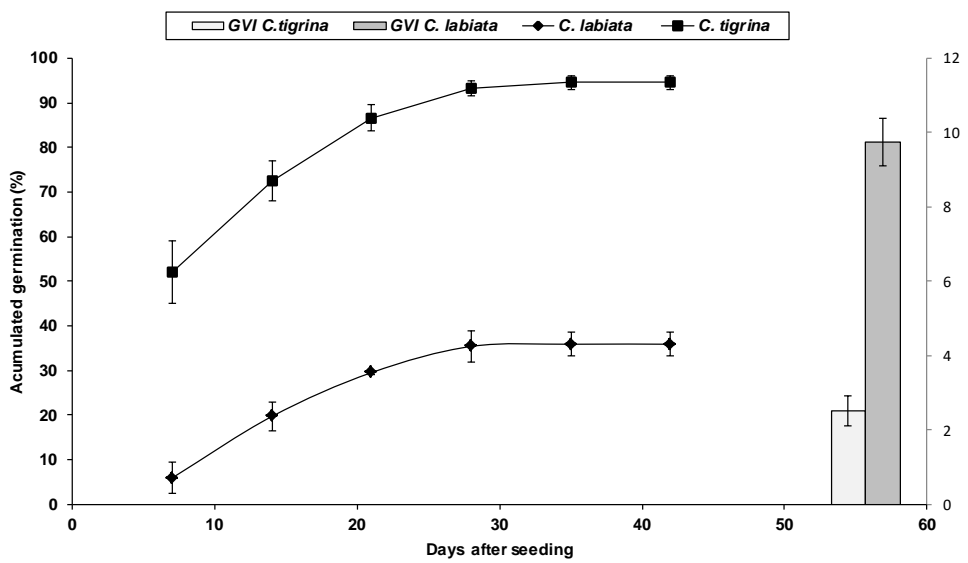

Fig 2. Cumulative assimbiotic germination (\%) and Germination Velocity index (GVI) of Cattleya tigrina and Cattleya labiata seed lots sown in $1 / 2$ MS medium. Bars are \pm Standard deviation.
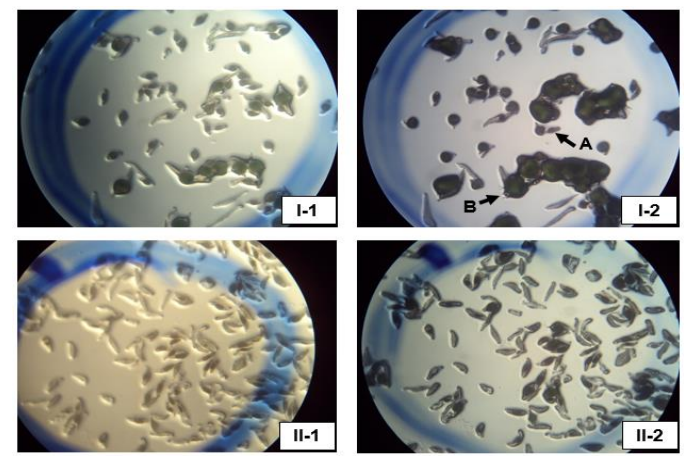

Fig 3. Asymbiotic germination of Cattleya tigrina and Cattleya labiata seeds in $1 / 2$ MS medium for 42 days. I- 1 seventh day field photograph after Cattleya tigrina sowing; I-2 twenty-first day field photograph after Cattleya tigrina sowing, where A- not germinated seed; B- protocorm with rhizoids in development. II-1 field of view photography seven days after Cattleya labiata sowing; II-2 field of view photography twenty days after Cattleya labiata sowing. 

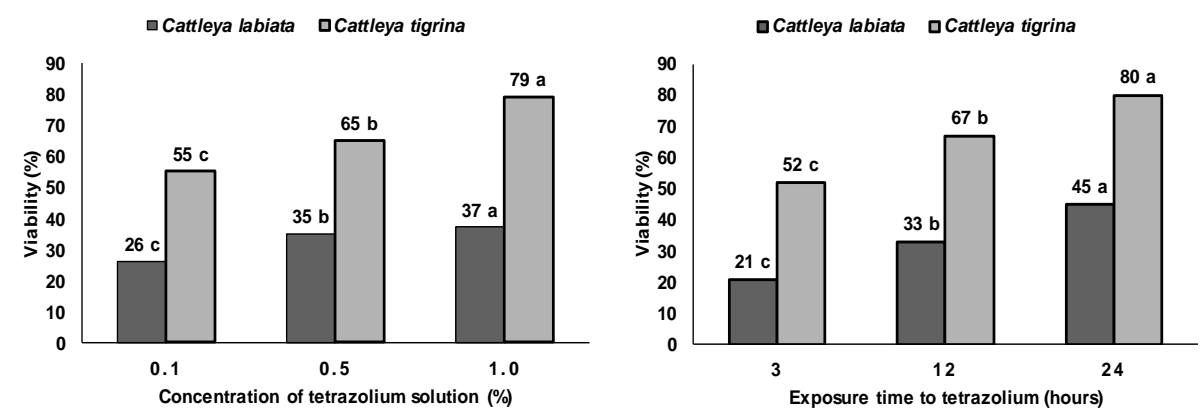

Fig 4. Cattleya labiata and Cattleya tigrina seed viability (\%), under different concentrations of tetrazolium solution and different exposure times. Means followed by the same letter do not differ on the same seed lot, by Tukey test at 5\% probability.

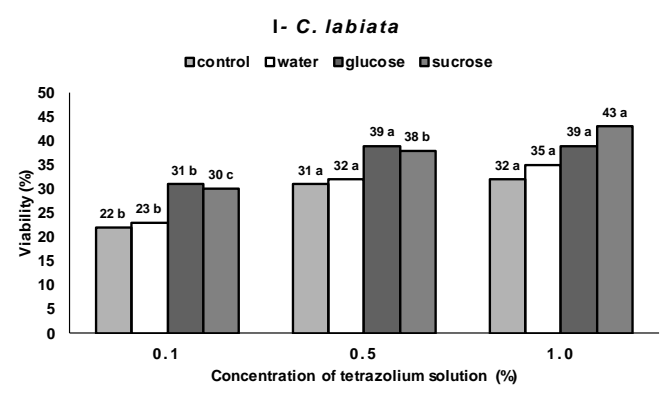

II- C. labiata

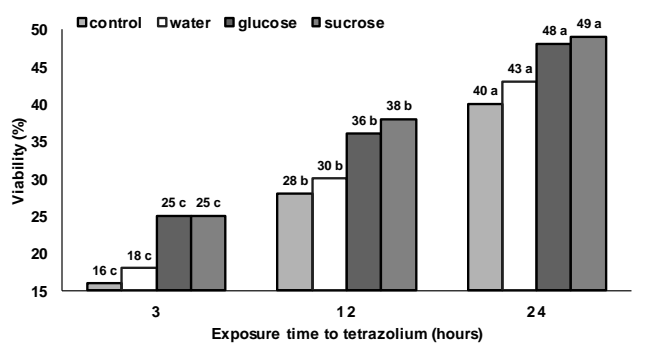

Fig 5. Cattleya labiata seed viability (\%) under four different preconditioning conditions; I- seed viability at different concentrations of tetrazolium solution; II- seed viability at different exposure times to tetrazolium solution. Means followed by the same letter do not differ in the same preconditioning treatment, by Tukey test at $5 \%$ probability.
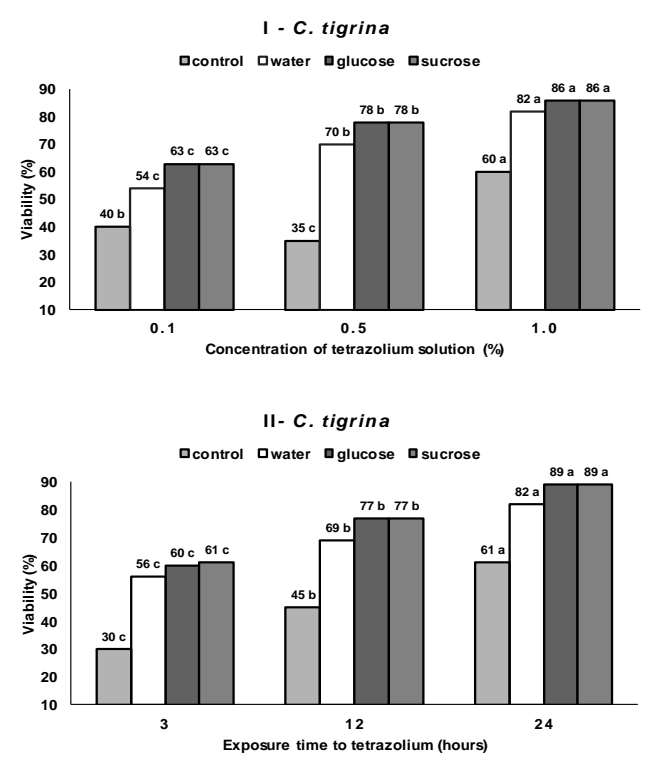

Fig 6. Cattleya tigrina seed viability (\%) under four different preconditioning conditions; I- seed viability at different concentrations of tetrazolium solution; II- seed viability at different exposure times to tetrazolium solution. Means followed by the same letter do not differ in the same treatment preconditioning, by Tukey test at $5 \%$ probability. 

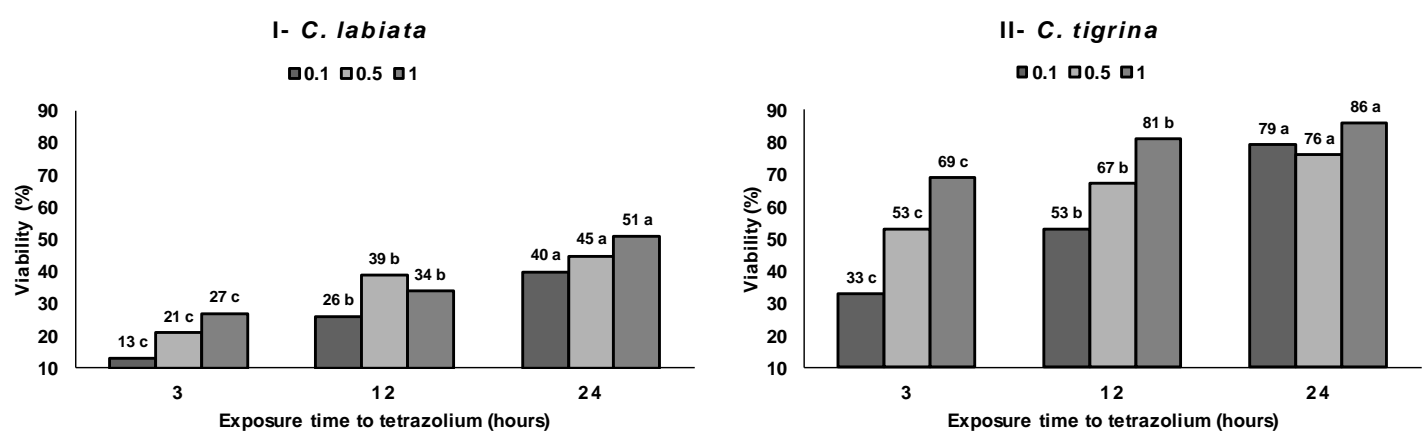

Fig 7. Cattleya labiata (I) and Cattleya tigrina (II) seed viability (\%) under different concentrations of tetrazolium solution, at different times of exposure. Means followed by the same letter do not differ at the same concentration of tetrazolium solution, by Tukey test at $5 \%$ probability.
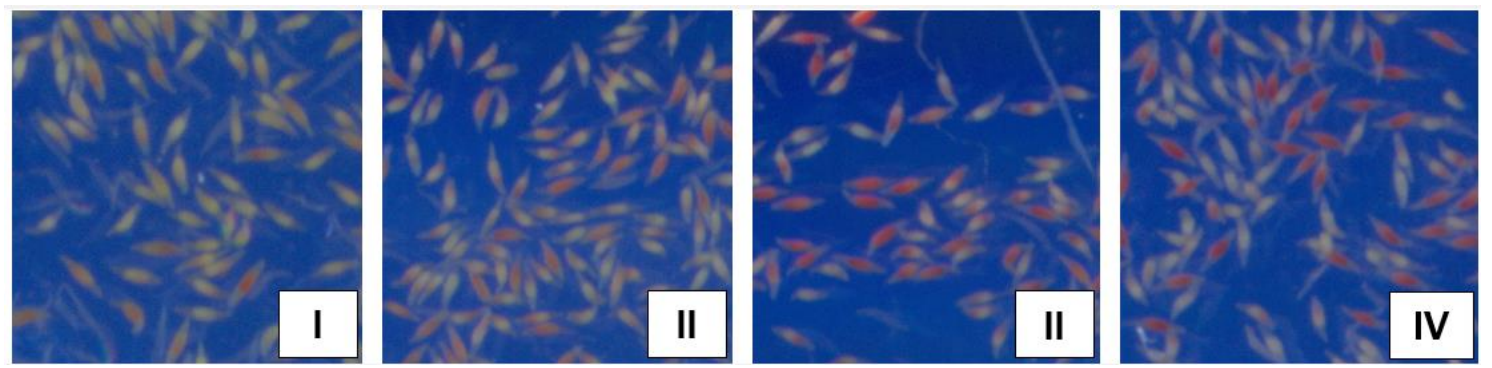

Fig 8. Cattleya labiata seeds subjected to tetrazolium test under different conditions of preconditioning, concentrations of tetrazolium salt, exposure times to tetrazolium solution and buffer solution use for tetrazolium salt dilution. I - Seeds without preconditioning, submitted to $0.1 \%$ tetrazolium solution for 3 hours; II - Seeds preconditioned in water, submitted to $1.0 \%$ tetrazolium solution for 24 hours; III - Seeds preconditioned in $10 \%$ glucose solution, submitted to $1.0 \%$ tetrazolium solution for 24 hours; IV - Seeds preconditioned in $10 \%$ sucrose solution, submitted to $1.0 \%$ tetrazolium buffered solution for 24 hours.

For $C$. tigrina seeds, the analysis of the interaction between preconditioning and concentration of the tetrazolium solution showed the same behavior: for all types of preconditioning performed, using $1.0 \%$ tetrazolium solution was statistically better, followed by concentration of $0.5 \%$. Beyond that, for seeds without preconditioning (control), viability values were smaller, and the $0.1 \%$ tetrazolium solution showed better results than $0.5 \%$ (Figure 6-I).

Figure 6-II shows the results from the interaction between type of preconditioning and seeds exposure time to tetrazolium solution. The use of $10 \%$ sucrose or glucose solutions presented similar results: the detection of viability was highest in seeds soaked for 24 hours, followed by 12 hours. Control has shown that as well as C. labiata, C. tigrina had the lowest viability values in all exposure times to tetrazolium solution.

The analysis of the interaction between tetrazolium concentration and exposure time of $C$. labiata seeds to the tetrazolium solution (Figure 7-I) has shown that the higher the concentration of tetrazolium solution and the exposure time to it, the better detection of seeds viability. For values of $0.1 \%, 0.5 \%$ and $1.0 \%, 24$ hours of exposure time had more significant differences (Figure 7-I).

For C. tigrina (Figure 7-II), $0.1 \%, 0.5 \%$ and $1.0 \%$ concentrations showed similar results, and 3 hours of exposure provided the lowest viability values, followed by 12 hours and 24 hours, which provided the best statistical results. For seed soaked in tetrazolium solution for 24 hours, the best results were obtained with the use of $1.0 \%$ solution. However, under these conditions, soaking in $0.1 \%$ tetrazolium solution showed a higher elevation than in $0.5 \%$ solution. Triticale seeds (x Triticosecale Wittmack) - a hybrid between wheat (Triticum aestivum) and rye (Secale cereale) - embedded between papers soaked in $1.0 \%$ tetrazolium solution, for 18 hours, at $40^{\circ} \mathrm{C}$, also showed better results when compared to lower concentrations of tetrazolium salt (Souza et al., 2010). For Soares et al. (2014), the use of high concentrations of tetrazolium salt may provide a reverse response to the test, due to morphological characteristics of the seeds and their small size. This is because, in this situation, instead of tetrazolium solution infiltrate seed tissue, seed loses water to the solution, complicating the viability identification. In this study, considering that seeds had undergone preconditioning in $10 \%$ sucrose or glucose solutions, this water loss should not have occurred, allowing better reaction between higher concentrations of salt and embryonic tissues. Preconditioning in $10 \%$ sucrose or glucose solution, the use of $1.0 \%$ tetrazolium solution and seeds exposure to tetrazolium for 24 hours are critical to improve the color of the seeds and minimize analysis errors. According to Arditti (1992) and Pridgeon et al. (1999), tetrazolium solution infiltration into orchid seeds can be difficult because their surface is generally provided with ornaments that facilitate dispersal, but difficult soaking. Thus, preconditioning would be important to allow a longer contact of seeds with sucrose solution, favoring water gain and the activation of respiratory chain enzymes in the embryo, before seed exposure to tetrazolium solution (Custódio et al., 2016). Lallana and Garcia (2013) indicate that for Trichocentrum jonesianum orchid seeds, preconditioning in water would be enough to improve the results of tetrazolium test. Figure 8 shows that seeds tested 
without preconditioning exhibit a fainter coloration, hampering test reading. Seeds preconditioned in sugar solution - either glucose or sucrose - and exposed for 24 hours to $1.0 \%$ tetrazolium solution exhibited easily detectable staining, facilitating determination of viable seeds.

In line with Hosomi et al. (2012), preconditioning in $10 \%$ sucrose solution allowed to establish a high correlation between the results obtained in tetrazolium test and germination test of Cattleya orchid seeds. Regarding the type of sugar used in preconditioning, these data do not indicate significant differences between glucose and sucrose. However, as an economic issue and ease of obtainment, it is recommended the use of sucrose.

\section{Materials and methods}

\section{Seed material}

Cattleya tigrina and Cattleya labiata fruits were collected at Aurora Orchid House, located in Taciba (São Paulo, Brazil) on 06/06/2009 and 23/05/2010, respectively. After collected, fruits were placed in paper envelopes and kept at room temperature until dehiscence. After dehiscence, seeds were cleaned and stored in paper envelope over silica gel, at $4{ }^{\circ} \mathrm{C}$, at $4.5 \%$ relative humidity (Brazil, 2009). After, seeds were placed in microtubes, which were kept in glass jars containing silica gel, sealed airtight and stored at $-18{ }^{\circ} \mathrm{C}$ until the experiments begun. They were stored for 24 and 13 months, respectively, at $4.5 \%$ relative humidity and $-18{ }^{\circ} \mathrm{C}$.

\section{Germination test}

Germination test was carried out in MS medium added with sucrose $\left(20\right.$ g.L $\left.\mathrm{L}^{-1}\right)$ and agar $\left(6\right.$ g.L $\left.\mathrm{L}^{-1}\right)$. The $\mathrm{pH}$ was adjusted to 5.6 with $\mathrm{NaOH}$ and the culture media autoclaved for subsequent distribution into $60 \mathrm{~mm}$ Petri dishes. Prior to sowing, $20 \mathrm{mg}$ of each seed batch were disinfected with 5 g. $\mathrm{L}^{-1}$ sodium dichloroisocyanurate for 10 minutes, and the addition of a few drops of Tween 80, inside syringes, at laminar flow cabinet (Machado Neto; Custódio, 2005). After this procedure, seeds were washed two times with autoclaved distilled water and then $1.0 \mathrm{~mL}$ of seed solution was dripped in each Petri dish. Afterwards the dishes were wrapped with plastic film and transferred to a growth chamber at temperature $25 \pm 3{ }^{\circ} \mathrm{C}$, with 16 hours photoperiod, for about 50 days.

Germination counting was scored in three fields in each plate, which were photographed with a Sony DSC-P10 digital camera, manually coupled to the stereoscopic microscope ocular lenses. All fields were photographed every seven days, kept in the same position. Images were analyzed on the computer and modified, when necessary, using the Adobe Photoshop ${ }^{\circledR}$ software CC 2015 through image magnification tools, contrast and brightness setting. Seeds that had expanded embryos and green cell mass (stage 1) were considered germinated according to Seaton and Hailes (1989). For each seed lot, three Petri dishes were sown, with three count fields in each one. The viability of orchid seeds, checked by tetrazolium test and germination rate was expressed as a percentage.

\section{Tetrazolium test}

For tetrazolium test, treatments were arranged in a factorial $4 \times 3 \times 3 \times 2$ for each seed lot. It was used two lots of seeds (Cattleya tigrina and Cattleya labiata); four ways preconditioning: (i) samples without preconditioning, (ii) samples with preconditioning in sucrose $10 \%$ solution, (iii) samples with preconditioning in glucose $10 \%$ solution and (iv) samples with preconditioning water; three periods of seed exposure to tetrazolium solution ( 3,12 and 24 hours) at three concentrations of tetrazolium salt $(0.1 ; 0.5$ and $1.0 \%)$ and two dilutions of tetrazolium salt - in water and in phosphate buffer solution. The buffer was prepared according to Dübbern de Souza (1994).

A precision scale $(0.00001 \mathrm{~g})$ was used to weigh up about $20 \mathrm{mg}$ of each seed sample (C. tigrina and C. labiata). Seeds were immediately transferred to $1.5 \mathrm{~mL}$ microtubes and submitted to the different preconditioning procedures.

Seed preconditioning was accomplished by adding $1.5 \mathrm{~mL}$ of water or $1.5 \mathrm{ml}$ of $10 \%$ sucrose solution or $1.5 \mathrm{ml}$ of $10 \%$ glucose solution to the microtubes for 24 hours at room temperature. After this period, the solutions were removed with Pasteur pipettes and the seeds were washed twice with distilled water. $1.5 \mathrm{ml}$ of tetrazolium solution, in different concentrations, was added to the microtubes, which were placed in water bath, in the dark, at $40{ }^{\circ} \mathrm{C}$, for the determined times. After incubation, microtubes were conserved in refrigerator to later enable image capturing on flatbed scanner and seed counting. Seed viability evaluation was based on capture and expansion of scanned images. After incubation period, $1.0 \mathrm{ml}$ of each sample was discarded and the remaining was dripped on a glass slide. Scanning and image capture were performed on HP Scanjet G2710 flatbed scanner with 3200 dpi resolution. Seed counting was carried out on computer screen and modified, when necessary, through image magnification tools and treatment of contrast and brightness with common image software. Seeds carrying red colored embryos were considered viable.

Detailed view of orchid seeds depends on the use of magnifying instruments, given its small size. Once the instruments for this purpose are expensive and difficult to access for most nurseries and small laboratories, the alternative found was image digitalization of seeds submitted to tetrazolium test (Figure 1), as indicated by Hosomi et al. (2011). Red or pink colored seeds were considered viable and white seeds were considered dead. The use of scanned images allows image documentation into digital files and simultaneous interpretation by more than one analyst, at laboratories located in different parts of the world (Custódio et al., 2012).

\section{Statistical analysis}

Orchid seed viability was expressed as a percentage. Germination Velocity Index (GVI) for each seed lot tested was calculated by using a modification of Maguire (1962), as follows: $G V I=\frac{G 1}{n 1}+\frac{G 2}{n 2}+\cdots .+\frac{G n}{n i}$ where $G 1$ to Gn were the seeds germinated in each of the counting periods and $n l$ to $n i$ were the number of days in each counting period. The design was completely randomized and the means comparison was made by Tukey test at $5 \%$ probability. Data analysis was performed by SISVAR® program (Ferreira, 2014).

\section{Conclusion}

Tetrazolium test results for orchid seed preconditioned in $10 \%$ glucose solution or $10 \%$ sucrose solution proved to be suitable for better identification of viable seeds. The use of buffer in the dilution of tetrazolium salt showed no significant difference in relation to dilution in water. The higher viability values were detected for both seed lots when they were tested with $1.0 \%$ tetrazolium solution for 24 hours. 


\section{Acknowledgements}

We would like to thanks to UNOESTE for the students scholarship and for the facilities use.

\section{REFERENCES}

Alvarez-Pardo V, Ferreira AG (2006) Orchid seeds storage. Rev Braz Semen. 28:92-98.

Arditti J (1992) Fundamentals of orchid biology. Toronto: John Wiley \& Sons, 691p.

Bertolini V, Damon A, Velásquez, ANR (2011) Symbiotic germination of three species of epiphytic orchids susceptible to genetic erosion, from Soconusco (Chiapas, Mexico). Eur J Environ Sci. 1:60-68.

BRASIL Ministério da Agricultura e Reforma Agrária (2009) Rules for seed analysis. Brasília: SNDA/DNDV/CLAV.

Carvalho NM, Nakagawa J (2012) Seeds: Science, technology and production. 5.ed. Funep: Jaboticabal. 590 p.

Chase MW, Cameron KM, Freudenstein JV, Pridgeon AM, Salazar G, Van den Berg C, Schuiteman A (2015) An update classification of Orchidaceae. Bot J Linn Soc. 177:151-174.

Custódio CC (2005) Fast tests for seed vigour evaluation: a review. Colloq Agrar. 1(1): 29-41.

Custódio CC, Damasceno RL, Machado Neto NB (2012) Digitalized images for the interpretation of tetrazolium test of Brachiaria brizantha seeds. Rev Braz Semen. 34:334 341.

Custódio CC, Marks TR, Pritchard HW, Hosomi ST, Machado-Neto NB (2016) Improved tetrazolium viability testing in orchid seeds with a thick carapace (Dactylorhiza fuchsii) or dark seed coat (Vanda curvifolia). Seed Sci and Technol. 44:177-188.

Deepti S, Gayatri MC, Sitikantha S (2013) In vitro seed germination as an aid to conserve Aerides maculosum Lindl., an endemic and endangered orchid of Western Ghats, India. Int Pharma and Bio Sci. 4: (B) 478-486.

Deepti S, Gayatri MC, Sitikantha S (2015) In vitro seed germination and plant regeneration of an epiphytic orchid Aerides ringens (Lindl.) Fischer. Indian $\mathrm{J}$ Biotechnol. 14:574-580.

Dias MCLL, Alves SJ (2008) Avaliação da viabilidade de sementes de Panicum maximum Jacq pelo teste de tetrazólio. Rev Braz Semen. 30:152-158.

Dowling N, Jusaitis M (2012) Asymbiotic in vitro germination and seed quality assessment of Australian terrestrial orchids. Austr J Bot. 60(7):592-601.

Dübbern de Souza FH (1994) Preparation of neutral solutions of tetrazolium. Comunicado Técnico Embrapa, n.51. Available

http://old.cnpgc.embrapa.br/publicacoes/cot/COT51.html Accessed at April 21st, 2015.

Fay MF, Chase MW (2009) Orchid biology: from Linnaeus via Darwin to the $21^{\text {st }}$ century. Ann Bot. 104:359-364.

Ferreira DF (2014) Sisvar: a guide for its bootstrap procedures in multiple comparisons. Ciênc e Agrotecnol. 38: 109-112.

França Neto JB, Krzyzanowski FC, Costa NP (1998) Tetrazolium testing in soybean seeds. Londrina: EMBRAPA-CNPSo, 72p.

Hosomi ST, Custódio CC, Seaton PT, Marks TR, MachadoNeto NB (2012) Improved assessment of viability and germination of Cattleya (Orchidaceae) seeds following storage. In Vitro Cell and Dev Biol-Plant. 48:127-136.

Hosomi ST, Santos RB, Custódio CC, Seaton PT, Marks TR, Machado-Neto NB (2011) Pre-conditioning Cattleya seeds to improve the efficacy of the tetrazolium test for viability. Seed Sci and Technol. 39:178-189.

Lallana VH, García LF (2013) Effect of pretreatments in the viability test of Trichocentrum jonesianum (Orchidaceae) seeds. Investigación Agrar. 15:129-132.

Lazarotto M, Piveta G, Muniz MFB, Reiniger LRS (2011) Adequation of tetrazolium test for the evaluation of quality of Ceiba speciosa seeds. Semina: Ciênc Agrár. 32:12431250.

Macedo MC, Rosa DBCJ, Soares JS, Tatara MB, Hoffmann NTK, Rosa YBCJ (2014) Seed storage and acclimatization of Brassavola tuberculata Hook. Semina: Ciênc Agrár. 35:2883-2894.

Machado-Neto NB, Custódio CC (2005) A medium for noncommercial sowing of orchid seed. Selbyana 26(1-2):316317.

Maguire JD (1962) Speed of germination aid in selection and evaluation of seedling emergence and vigor. Crop Sci. 2:176-177.

Marcos-Filho J (2015) Seed vigor testing: an overview of the past, present and future perspective. Sci Agr. 72: 363-374.

Mendonça EAF, Coelho MFB, Luchese M (2006) Tetrazolium testing in seeds of mangaba-brava (Lafoensia pacari St. Hil. - Lythraceae). Rev Braz Plant Med. 8:33-38.

Oliveira LM, Carvalho MLM, Davide AC (2001) Using the tetrazolium testing for physiological evaluation of canafístula seeds (Peltophorum dubium (Sprengel) Tauber - Caesalpinoideae). Informativo ABRATES. 11:118.

Pridgeon AM, Cribb PJ, Chase MW, Rasmussen FN (Ed.) (1999) Genera Orchidacearum. General introduction, Apostasioideae, Cypripedioideae. Oxford: Oxford University; $64 \mathrm{p}$

Rasmussen HN (2011) Methods of studying field germination and seedling physiology: present potential and drawbacks. Eur J Environ Sci. 1: 55-59.

Reed BM, Sarasan V, Kane M, Bunn E, Pence VC (2011) Biodiversity conservation and conservation biotechnology tools. In Vitro Cell Dev Biol - Plant. 47:1-4.

Salazar-Mercado A (2012) Asymbiotic germination and in vitro development of seedlings of Cattleya mendelli Dombrain (Orchidaceae). Acta Agron. 61:69-78.

Seaton PT, Hailes NSJ (1989) Effect of temperature and moisture content on viability of Cattleya aurantiaca seed. In: Pritchard, H. W. (Ed). Modern methods in orchid conservation: the role of physiology, ecology and management. Cambridge: University Press, p. 17-29.

Soares JS, Jardim Rosa YBC, Tatara MB, Sorgato JC, Rosa Lemes CS (2014) Identification of orchid seed viability by the tetrazolium test. Semina: Ciênc Agrár. 35:2275-2284.

Souza CR, Ohlson OC, Gavazza MIA, Panobianco M (2010) Tetrazolium test for evaluating triticale seed viability. Rev Braz Semen. 32:163-169.

Swarts ND, Dixon KW (2009) Terrestrial orchid conservation in the age of extinction. Ann Bot. 104:543556.

Yam TW, Arditti J, Cameron KM (2009) "The Orchids Have Been a Splendid Sport" - an alternative look at Charles Darwin's contribution to orchid biology. Am J Bot. 96:2128-2154. 